\title{
Neutrophil-to-lymphocyte ratio predicts critical illness patients with 2019 coronavirus disease in the early stage
}

Jingyuan Liu ${ }^{1 \dagger}$, Yao Liư ${ }^{2 \dagger}$, Pan Xiang ${ }^{1}$, Lin Pu ${ }^{1}$, Haofeng Xiong ${ }^{1}$, Chuansheng Li ${ }^{1}$, Ming Zhang ${ }^{1}$, Jianbo Tan ${ }^{1}$, Yanli Xu3 ${ }^{3}$, Rui Song ${ }^{3}$, Meihua Song ${ }^{3}$, Lin Wang ${ }^{3}$, Wei Zhang ${ }^{3}$, Bing Han ${ }^{3}$, Li Yang ${ }^{2}$, Xiaojing Wang ${ }^{2}$, Guiqin Zhou², Ting Zhang ${ }^{4}$, Ben $\mathrm{Li}^{4}$, Yanbin Wang ${ }^{4^{*}}$, Zhihai Chen ${ }^{3^{*}}$ and Xianbo Wang ${ }^{2^{*}}$ (D)

\begin{abstract}
Background: Patients with critical illness due to infection with the 2019 coronavirus disease (COVID-19) show rapid disease progression to acute respiratory failure. The study aimed to screen the most useful predictive factor for critical illness caused by COVID-19.

Methods: The study prospectively involved 61 patients with COVID-19 infection as a derivation cohort, and 54 patients as a validation cohort. The predictive factor for critical illness was selected using LASSO regression analysis. A nomogram based on non-specific laboratory indicators was built to predict the probability of critical illness.

Results: The neutrophil-to-lymphocyte ratio (NLR) was identified as an independent risk factor for critical illness in patients with COVID-19 infection. The NLR had an area under receiver operating characteristic of 0.849 (95\% confidence interval [Cl], 0.707 to 0.991$)$ in the derivation cohort and 0.867 ( $95 \% \mathrm{Cl} 0.747$ to 0.944 ) in the validation cohort, the calibration curves fitted well, and the decision and clinical impact curves showed that the NLR had high standardized net benefit. In addition, the incidence of critical illness was 9.1\% (1/11) for patients aged $\geq 50$ and having an $\mathrm{NLR}<3.13$, and $50 \%$ (7/14) patients with age $\geq 50$ and NLR $\geq 3.13$ were predicted to develop critical illness. Based on the risk stratification of NLR according to age, this study has developed a COVID-19 pneumonia management process.

Conclusions: We found that NLR is a predictive factor for early-stage prediction of patients infected with COVID-19 who are likely to develop critical illness. Patients aged $\geq 50$ and having an NLR $\geq 3.13$ are predicted to develop critical illness, and they should thus have rapid access to an intensive care unit if necessary.
\end{abstract}

Keywords: COVID-19, 2019-nCoV, NLR, Model, Prognosis, SARS-CoV

*Correspondence: wangyanbin01@163.com; chenzhihai0001@126.com; wangxb@ccmu.edu.cn

${ }^{\dagger}$ Jingyuan Liu and Yao Liu contributed equally to this article

${ }^{2}$ Center of Integrative Medicine, Beijing Ditan Hospital, Capital Medical

University, No. 8 Jing Shun East Street, Beijing 100015, China

${ }^{3}$ Center of Infectious Diseases, Beijing Ditan Hospital, Capital Medical University, No. 8 Jing Shun East Street, Beijing 100015, China

${ }^{4}$ Liver Diseases Center, Beijing Ditan Hospital, Capital Medical University, No. 8 Jing Shun East Street, Beijing 100015, China

Full list of author information is available at the end of the article

\section{Background}

Coronavirus is a large virus family, members of which are known to cause common cold and serious illnesses, such as the Middle East respiratory syndrome and severe acute respiratory syndrome [1-4]. It was found that the 2019 coronavirus disease (COVID-19) was the cause of unexplained viral pneumonia in Wuhan, China in December 2019, and this virus was recognized by the World Health Organization on January 12, 2020. In the following month, COVID-19 was reported to spread throughout

(c) The Author(s) 2020. This article is licensed under a Creative Commons Attribution 4.0 International License, which permits use, sharing, adaptation, distribution and reproduction in any medium or format, as long as you give appropriate credit to the original author(s) and the source, provide a link to the Creative Commons licence, and indicate if changes were made. The images or other third party material in this article are included in the article's Creative Commons licence, unless indicated otherwise in a credit line to the material. If material is not included in the article's Creative Commons licence and your intended use is not permitted by statutory regulation or exceeds the permitted use, you will need to obtain permission directly from the copyright holder. To view a copy of this licence, visit http://creativeco mmons.org/licenses/by/4.0/. The Creative Commons Public Domain Dedication waiver (http://creativecommons.org/publicdomain/ zero/1.0/) applies to the data made available in this article, unless otherwise stated in a credit line to the data. 
the Hubei Province and China and even to other countries [5], causing 34,662 confirmed cases of infection by February 8, 2020.

Most patients infected with the novel coronavirus had mild and moderate illness, and severe illness often experienced dyspnea after 1 week. In cases of critical illness, patients progressed rapidly to acute respiratory failure, acute respiratory distress syndrome, metabolic acidosis, coagulopathy, and septic shock. Early identification of risk factors for critical illness facilitated appropriate provision of supportive care and rapid access to the intensive care unit (ICU) when required. For patients with mild and moderate illness, general isolation treatment is required and ICU-care is not needed unless the condition worsens. Thus, early prognosis prediction would help reduce mortality and alleviate the shortage of medical resources.

Of note, a high incidence of lymphopenia in COVID19 patients has been reported by Cao and his colleagues [6]. In addition, the baseline neutrophil-to-lymphocyte ratio (NLR) has been confirmed as a potential short-term prognostic indicator for patients with acute-on-chronic hepatitis B liver failure [7]. Thus, we wondered that whether NLR might be a potential predictor for critical illness of COVID-19. To test this hypothesis, we included 26 variables including NLR along with epidemiological history, comorbidity, and other laboratory tests for LASSO regression analysis.

\section{Methods}

\section{Patient selection}

This study was a prospective single-center study, which included 61 patients with COVID-19 infection treated at Beijing Ditan Hospital from January 13 to 31, 2020 as a derivation cohort, and 54 patients included from February 1 to 24, 2020 as a validation cohort. The inclusion criteria are as follows: (1) confirmed cases of COVID19, which was diagnosed based on the new coronavirus pneumonia diagnosis and treatment plan (trial version 5) developed by the National Health Committee of the People's Republic of China (http://www.nhc.gov.cn/). The diagnostic criteria are as follows: epidemiological history: within 14 days before the onset of COVID-19, there were travel history or residential history in Wuhan or surrounding areas, contact history of people with COVID-19, contact history of people with fever or respiratory symptoms from Wuhan or surrounding areas, contact history of people with fever or respiratory symptoms from the community which was confirmed to have COVID-19 cases; clinical manifestations: fever and/or respiratory symptoms, imaging characteristics of pneumonia, leukocyte count was normal or decreased, or the lymphocyte count was decreased. Etiological evidence: real-time polymerase chain reaction test of respiratory or blood samples was positive for the nucleic acid of COVID-19, and the viral gene sequencing of respiratory or blood samples was highly homologous with the known COVID-19. Confirmed case: any one of the epidemiological history, any two of the clinical manifestations, and any one of the etiological evidence; if there is no clear epidemiological history, any three of the clinical manifestations, and any one of the etiological evidence. (2) complete baseline characteristics at the onset time. The exclusion criterion was primary infection by influenza virus, parainfluenza virus, adenovirus, respiratory syncytial virus, rhinovirus, human metapneumovirus, SARS coronavirus, mycoplasma, chlamydia and bacteria. Clinical classification of COVID-19 pneumonia were done according to the new coronavirus pneumonia diagnosis and treatment plan (trial version 5) developed by the National Health Committee of the People's Republic of China (http://www.nhc.gov.cn/). The clinical classifications are as follows: (1) mild, slight clinical symptoms, no pneumonia manifestations on imaging. (2) moderate, with fever, respiratory tract symptoms, and imaging shows pneumonia. (3) severe, meet any of the following: (a) respiratory distress, respiratory rate $\geq 30$ beats/min; (b) in the resting state, mean oxygen saturation $\leq 93 \%$; (c) arterial blood oxygen partial pressure/oxygen concentration $\leq 300 \mathrm{mmHg}(1 \mathrm{mmHg}=0.133 \mathrm{kPa})$. (4) critical, meets any of the following: (a) respiratory failure occurs and requires mechanical ventilation; (b) Shock occurs; (c) ICU admission is required for combined organ failure.

\section{Data at onset}

All screened COVID-19 infection patients had upper respiratory tract (throat swab) samples taken upon admission; these samples were stored in virus transport medium and then transported to Beijing Center for Disease Control and Prevention for laboratory diagnosis by real-time polymerase chain reaction test. Influenza A virus (H1N1, H3N2, H7N9), influenza B virus, bacterium, and fungus detection in sputum or respiratory secretions was performed. Epidemiological history, comorbidity, vital signs, symptoms, signs, laboratory tests, including biochemical indicators, blood routine, C-reactive protein, chest radiograph, or CT scan were collected at onset time of COVID-19.

\section{Follow-up}

After admission, the patients were re-examined for laboratory indexes and imaging analysis, and recorded symptoms and signs, treatments and outcome events. The endpoint of this study was the development of critical illness. 


\section{Statistical analysis}

Age and days were represented as median (range), categorical variables by number (\%), and laboratory data by mean (interquartile range). The cutoff values of neutrophil-to-lymphocyte ratio (NLR) and age were calculated based on the maximum Youden index (sensitivity + specificity - 1). Comparison of the differences between the two cohorts was conducted using the t-test, Chi-square test, or Mann-Whitney U test. Multivariate Cox proportional hazards regression analyses (stepwise forward method) were performed to identify the most useful predictive factor for predicting critical illness incidence. p-value $<0.05$ was considered statistically significant. Analyses were performed using SPSS 22.0 statistical package (SPSS, Inc., Chicago, IL, USA).

$\mathrm{R}$ software version 3.6.3 (R Foundation for Statistical Computing, Vienna, Austria) was used to establish LASSO regression analysis, nomogram, Harrell concordance index, calibration, decision and clinical impact curves. LASSO regression is a type of machine learning regression, which was used to select independent risk factors that affect outcomes. The regression was generated using the glmnet package in R. Harrell's concordance index is routinely used to measure how well a variable or model predicts the time to a censored event. The index was generated using the rms package in $R$ [8]. The calibration curve reflects the relationship between the prediction rate and the actual occurrence rate. The curve was also generated using the rms package in $R$. The abscissa is the prediction probability. The prediction model is used to predict the probability of the event, and 0 to 1 means the probability of the event is 0 to $100 \%$. The ordinate is the actual probability (actual incident rate) of the patient. The red line is the fit line, which represents the actual value corresponding to the predicted value [9]. The decision curve is a useful tool to evaluate the clinical application of the model, which displays estimates of the standardized net benefit by the probability threshold used to categorize observations as 'high risk.' The clinical impact curve is an alternative plot for the output of the decision curve. Decision and clinical impact curves were generated using the DecisionCurve package in R [10].

\section{Results}

\section{Derivation and validation cohort characteristics}

Of the 61 patients with COVID-19 infection included in the derivation cohort, the infections of $44(72.1 \%)$ were diagnosed as mild or moderate and those of 17 (27.9\%) were diagnosed as severe or critical on admission. In the validation cohort, the infections of $34(63.0 \%)$ were diagnosed as mild or moderate and those of 20 (37.0\%) were diagnosed as severe or critical. None of the 115 patients had a history of Huanan seafood market exposure in Wuhan. 44 of patients $(72.1 \%)$ with pneumonia caused by COVID-19 infection in the derivation cohort were Wuhan citizens or visited Wuhan recently, but 44 of patients $(81.5 \%)$ in the validation cohort had not left Beijing recently, but had a close exposure history with COVID-19. There was no significant difference between the two cohorts in terms of comorbidity (Table 1). Among the 61 patients in the derivation cohort, $5(8.2 \%)$ had high fever $\left(>39^{\circ} \mathrm{C}\right), 3(4.9 \%)$ had dyspnea. 7 (11.5\%) had mild shortness of breath. 11 (18.0\%) patients had gastrointestinal symptoms. The laboratory test showed that the white blood cell count, neutrophil count, lymphocyte count, and platelet count in the validation cohort was significantly higher than that in the derivation cohort (Table 1).

The median time from illness onset to admission was 5 days in the derivation cohort and 7 days in the validation cohort. All patients were isolated after admission, in the derivation cohort, 34 (55.7\%) patients received antiviral treatment, of which eight patients received oseltamivir (75 mg every $12 \mathrm{~h}$, orally) and 26 (42.6\%) patients received lopinavir and ritonavir tablets $(200 \mathrm{mg}$ twice daily, orally). Nearly half of the patients $(26,42.6 \%)$ in the derivation cohort received antibiotic therapy. One patient received methylprednisolone for 3 days before admission and stopped using this drug after admission at the hospital, another patient had been taking methylprednisolone $8 \mathrm{mg}$ every other day for 10 months to treat optic neuromyelitis and continued taking it after admission. 20 (32.8\%) patients in the derivation cohort received oxygen support and $52(85.2 \%)$ received nebulization inhalation therapy, three patients among these received non-invasive ventilation and two received invasive mechanical ventilation. Nebulization inhalation drugs included recombinant human interferon $\alpha 2 b$ and acetylcysteine. By the end of Jan 31, no patients had died, three patients were discharged, and the remaining patients were in hospital, of which eight patients progressed to critical illness and received treatment in the ICU (Table 1).

X-ray or CT showed multiple lung lobe or bilateral involvement in $48(78.7 \%)$ patients. Figure 1 showed the CT images of a typical patient in early, consolidation, absorption and dissipation stages.

\section{Predictive factors of critical illness}

Twenty-six variables were included in the LASSO regression analysis. The variables were demographic status (sex, age, smoking, and drinking history), comorbidity (diabetes, hypertension, and chronic obstructive pulmonary disease [COPD]), CT scan (multiple lung lobe or bilateral involvement), timeline after onset of illness (days from illness onset to admission time), routine blood tests 
Table 1 Demographics and characteristics of patients infected with COVID-19

\begin{tabular}{|c|c|c|c|}
\hline & Derivation cohort $(n=61)$ & Validation cohort $(n=54)$ & $p$ value \\
\hline \multicolumn{4}{|l|}{ Characteristics } \\
\hline Age, years & $40(1-86)$ & $45(1-92)$ & 0.983 \\
\hline Gender & & & 0.268 \\
\hline Male & $31(50.8)$ & $33(61.1)$ & \\
\hline Female & $30(49.2)$ & $21(38.9)$ & \\
\hline Current smoking & $4(6.6)$ & $6(11.1)$ & 0.387 \\
\hline Drinking & $13(21.3)$ & $12(22.2)$ & 0.906 \\
\hline \multicolumn{4}{|l|}{ Exposure } \\
\hline Wuhan residents come to Beijing & $44(72.1)$ & $10(18.5)$ & $<0.0001$ \\
\hline \multicolumn{4}{|l|}{ Comorbidity } \\
\hline Diabetes & $5(8.2)$ & $5(9.3)$ & 0.840 \\
\hline Hypertension & $12(19.7)$ & $13(24.1)$ & 0.568 \\
\hline Cardiovascular disease & $1(1.6)$ & $3(5.6)$ & 0.253 \\
\hline Chronic obstructive pulmonary disease & $5(8.2)$ & $1(1.9)$ & 0.127 \\
\hline Disease type on admission this hospital & & & 0.071 \\
\hline Mild & $5(8.2)$ & $9(16.7)$ & \\
\hline Moderate & $39(63.9)$ & $25(46.3)$ & \\
\hline Severe & $14(23.0)$ & $15(27.8)$ & \\
\hline Critical & $3(4.9)$ & $5(9.3)$ & \\
\hline \multicolumn{4}{|l|}{ Signs and symptoms } \\
\hline \multicolumn{4}{|l|}{ Highest temperature, ${ }^{\circ} \mathrm{C}$} \\
\hline $37.3-38.0$ & $21(34.4)$ & $13(24.1)$ & 0.225 \\
\hline $38.1-39.0$ & $34(55.7)$ & $25(46.3)$ & 0.312 \\
\hline$>39.0$ & $5(8.2)$ & $4(7.4)$ & 0.875 \\
\hline Dyspnea & $3(4.9)$ & $4(7.4)$ & 0.577 \\
\hline Mild shortness of breath & $7(11.5)$ & $12(22.2)$ & 0.121 \\
\hline Cough & $39(63.9)$ & $38(70.4)$ & 0.464 \\
\hline Sputum production & $27(44.3)$ & $22(40.7)$ & 0.703 \\
\hline Fatigue & $35(57.4)$ & $26(48.1)$ & 0.322 \\
\hline Headache & $21(34.4)$ & $6(11.1)$ & 0.003 \\
\hline Chill & $12(19.7)$ & $9(16.7)$ & 0.677 \\
\hline Anorexia & $8(13.1)$ & $6(11.1)$ & 0.743 \\
\hline Nausea or vomiting & $5(8.2)$ & $5(9.3)$ & 0.840 \\
\hline Diarrhea & $6(9.8)$ & $2(3.7)$ & 0.197 \\
\hline Sore throat & $10(16.4)$ & $8(14.8$ & 0.816 \\
\hline Chest pain & $1(1.6)$ & $0(0)$ & 0.345 \\
\hline Systolic pressure $<90$ or diastolic pressure $\leq 60, \mathrm{mmHg}$ & $5(8.2)$ & $6(11.1)$ & 0.596 \\
\hline Respiratory rate $>30$ breaths per min & $2(3.3)$ & $4(7.4)$ & 0.320 \\
\hline \multicolumn{4}{|l|}{ Blood laboratory findings } \\
\hline White blood cell count, $\times 10^{9} / \mathrm{L}$ & $4.3(3.5-5.1)$ & $5.4(4.1-7.0)$ & $<0.0001$ \\
\hline Neutrophil count, $\times 10^{9} / \mathrm{L}$ & $2.5(2.1-3.5)$ & $3.0(2.1-4.6)$ & 0.036 \\
\hline Lymphocyte count, $\times 10^{9} / \mathrm{L}$ & $1.0(0.8-1.4)$ & $1.3(1.0-1.9)$ & 0.011 \\
\hline Monocyte count, $\times 10^{9} / \mathrm{L}$ & $0.3(0.2-0.4)$ & $0.3(0.2-0.4)$ & 0.079 \\
\hline NLR & $2.6(1.6-3.5)$ & $2.3(1.5-3.9)$ & 0.676 \\
\hline C-reactive protein, mg/L & $12.0(3.7-27.8)$ & $21.6(1.9-87.4)$ & 0.184 \\
\hline Hemoglobin, g/L & $138.0(127.0-150.5)$ & $139.0(127.8-147.0)$ & 0.773 \\
\hline Platelet count, $\times 10^{9} / \mathrm{L}$ & $164.0(135.0-219.5)$ & 205.5 (149.8-263.6) & 0.013 \\
\hline Prothrombin time, s & $12.0(11.1-13.1)$ & $12.2(11.8-13.1)$ & 0.191 \\
\hline Potassium, mmol/L & $3.8(3.5-4.1)$ & $3.8(3.6-4.2)$ & 0.408 \\
\hline
\end{tabular}


Table 1 (continued)

\begin{tabular}{|c|c|c|c|}
\hline & Derivation cohort $(n=61)$ & Validation cohort $(n=54)$ & $p$ value \\
\hline Sodium, mmol/L & $139.0(137.0-140.0)$ & $138.5(136.4-139.7)$ & 0.112 \\
\hline Serum Chlorine, mmol/L & $102.0(100.0-104.0)$ & $102.3(100.2-105.3)$ & 0.796 \\
\hline Serum urea nitrogen, $\mathrm{mmol} / \mathrm{L}$ & $4.3(3.5-5.6)$ & $4.3(3.4-5.5)$ & 0.989 \\
\hline Creatinine, $\mu \mathrm{mol} / \mathrm{L}$ & $60.0(47.0-69.5)$ & $69.3(51.6-80.1)$ & 0.069 \\
\hline Serum glucose, mmol/L & $6.1(5.5-6.9)$ & $5.9(5.2-7.7)$ & 0.407 \\
\hline Creatine kinase, $\mathrm{U} / \mathrm{L}$ & $93.0(57.0-137.0)$ & $89.4(63.7-141)$ & 0.643 \\
\hline Alanine aminotransferase, $U / L$ & $19.0(14.0-33.5)$ & $23.7(13.9-35.4)$ & 0.295 \\
\hline Albumin, $g / L$ & $44.0(40.5-47.0)$ & $41.1(36.2-44.2)$ & 0.005 \\
\hline Multiple lung lobe or bilateral involvement & $48(78.7)$ & $37(68.5)$ & 0.743 \\
\hline With bacterial infection & $8(13.1)$ & $6(11.1)$ & 0.231 \\
\hline \multicolumn{4}{|l|}{ Timeline after onset of illness, median (range) } \\
\hline Days from illness onset to admission time & $5(0-23)$ & $7(0-21)$ & 0.042 \\
\hline Days from illness onset to dyspnea & $3(2-11)$ & $7(0-9)$ & 0.906 \\
\hline Days from illness onset to ICU admission & $9(2-14)$ & $10(4-14)$ & 0.643 \\
\hline \multicolumn{4}{|l|}{ Treatment } \\
\hline Antiviral therapy & $34(55.7)$ & $36(66.7)$ & 0.231 \\
\hline Antibiotic therapy & $26(42.6)$ & $21(38.9)$ & 0.684 \\
\hline Use of corticosteroid & $2(3.3)$ & $3(5.6)$ & 0.550 \\
\hline Oxygen support & $20(32.8)$ & $24(44.4)$ & 0.199 \\
\hline Nasal cannula & $15(24.6)$ & $19(35.2)$ & \\
\hline Non-invasive ventilation & $3(4.9)$ & $2(3.7)$ & \\
\hline Invasive mechanical ventilation & $2(3.3)$ & $3(5.6)$ & \\
\hline Nebulization inhalation & $52(85.2)$ & $49(90.7)$ & 0.368 \\
\hline \multicolumn{4}{|l|}{ Outcomes } \\
\hline Dead & $0(0)$ & $1(1.9)$ & 0.286 \\
\hline Transfer to ICU & $8(13.1)$ & $6(11.1)$ & 0.743 \\
\hline Discharge & $3(4.9)$ & $19(35.2)$ & $<0.0001$ \\
\hline Hospitalization & $50(82.0)$ & $28(51.9)$ & 0.001 \\
\hline
\end{tabular}

Data are median (range), $\mathrm{n}(\%)$, or median (interquartile range)

COVID-19 2019 novel coronavirus, NLR neutrophil-to-lymphocyte ratio, NA not applicable, ICU intensive care unit

$\mathrm{p}$ values comparing mild group and severe group are from $\mathrm{X}^{2}$ test, or Mann-Whitney $\mathrm{U}$ test

(white blood cell count, neutrophil count, lymphocyte count, monocyte count, NLR, hemoglobin levels, and platelet count), liver function (alanine aminotransferase, albumin, prothrombin time), serum electrolytes (potassium, sodium, and chlorine), kidney function (serum urea nitrogen and creatinine), serum glucose, and C-reactive protein. Age, NLR, and hypertension of the 61 individuals in the cohort were prognostic factors for critical illness incidence when the partial likelihood deviance was the smallest; NLR was the significant predictive factor when the lambda was 1 standard error (Fig. 2a, b). The three factors mentioned above were included in the multivariate COX regression analysis, and the results indicated that age and NLR are prognostic factors for critical illness of COVID-19 infection. However, when the hazard ratios (HR) of age was close to 1 , age was transformed into a categorical variable ( $<50$ years $/ \geq 50$ years) based on cutoff value, and then the three variables were included in the COX regression analysis again. Finally, NLR was selected as the most useful predictive factor for predicting critical illness incidence.

\section{Nomogram establishment and validation}

The nomogram was established based on the NLR values, which were used to predict the critical rates of 7 and 14 days (Fig. 3). The nomogram had a concordance index (c-index) of 0.807 (95\% confidence interval [CI] $0.676-0.938$ ) for predicting the critical probability in the derivation cohort and 0.882 (95\% CI 0.778-0.986) in the validation cohort. The calibration curves showed that the predicted rates were in agreement with the actual results observed in the derivation and validation cohorts (Fig. 4a, d). The vertical lines on the upper side reflect the distribution of the predicted probability in patients. The decision curve and clinical impact curve showed that the 


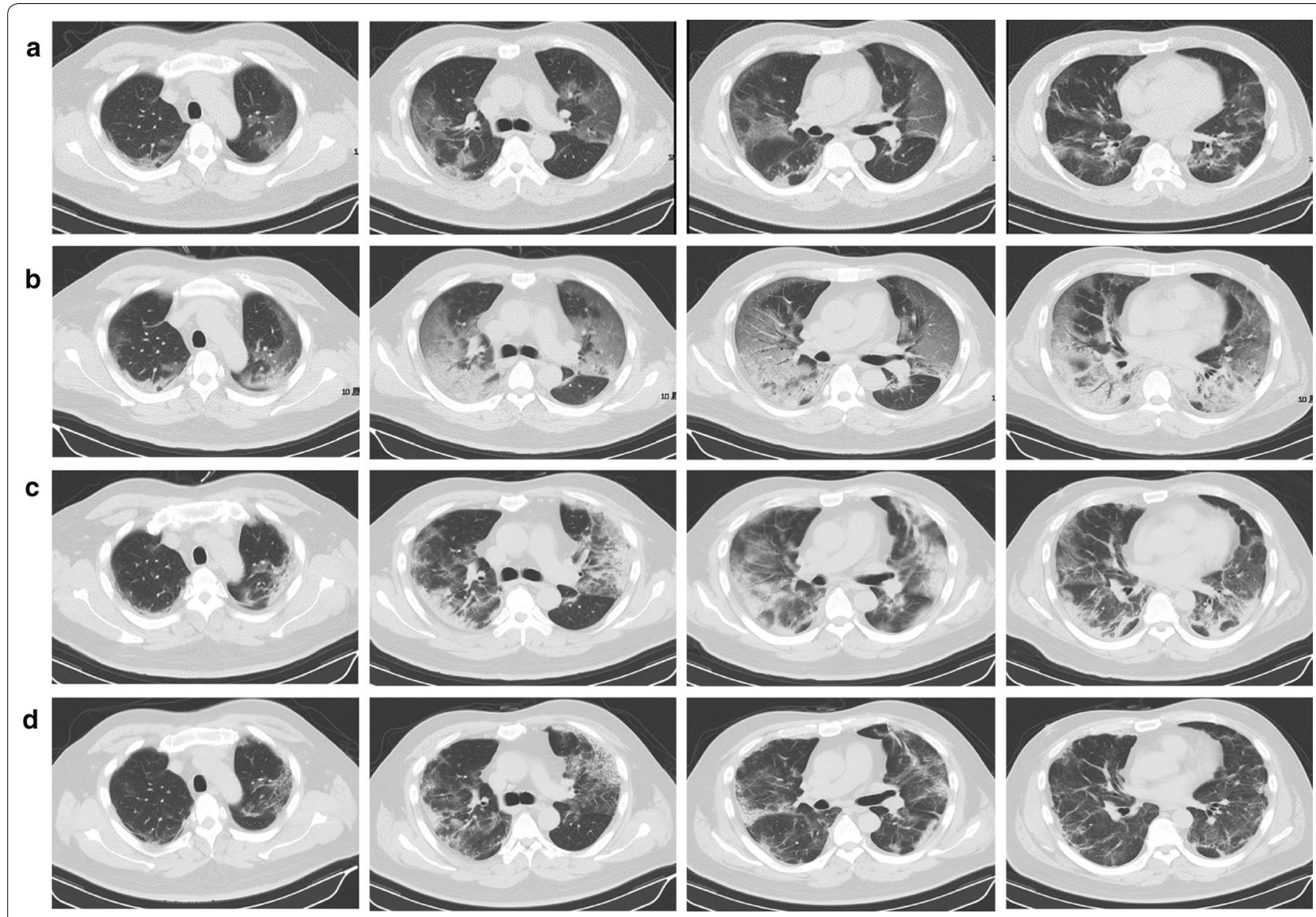

Fig. 1 A 50-year-old man with 2019 novel coronavirus (COVID-19) infection. a Ground glass shadow in multiple lobes and segments of bilateral lungs; the lesions were adjacent to the pleura (IIlness Day 8, Hospital Day 0). b Ground glass shadow expanding and consolidation in bilateral lung (IIlness Day 11, Hospital Day 3).c Ground glass shadow absorption and reduced consolidation area (Illness Day 15, Hospital Day 7). d Lesion dissipation (IIlness Day 20, Hospital Day 12)
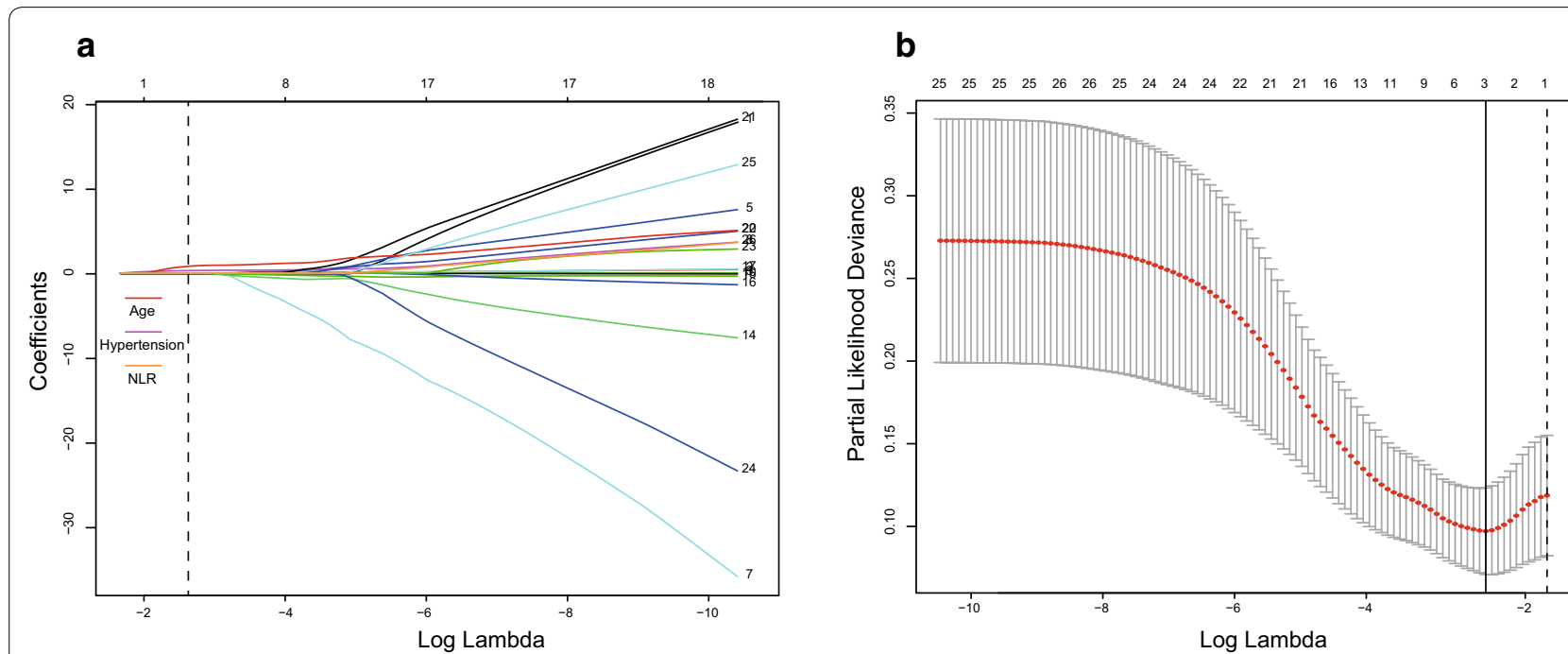

Fig. 2 The predictive factor neutrophil-to-lymphocyte ratio (NLR) was selected using LASSO regression analysis. a LASSO coefficient profiles of the non-zero variables of COVID-19 pneumonia. b Partial likelihood deviance plot of the lowest point of the red curve (solid line), which corresponds to a three-variable model. The dashed line on the right is a more concise model within one standard error (the number of variables is one) 
NLR

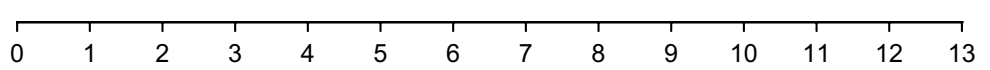

7-day critical probabilities

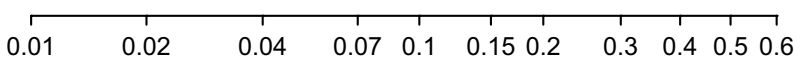

14-day critical probabilities $\begin{array}{lllllllllllll}0.04 & 0.07 & 0.1 & 0.15 & 0.2 & 0.3 & 0.4 & 0.5 & 0.6 & 0.7 & 0.8 & 0.90 .95 & 0.99\end{array}$

Fig. 3 Nomogram predicting 7-day and 14-day critical probability of patients with COVID-19 pneumonia
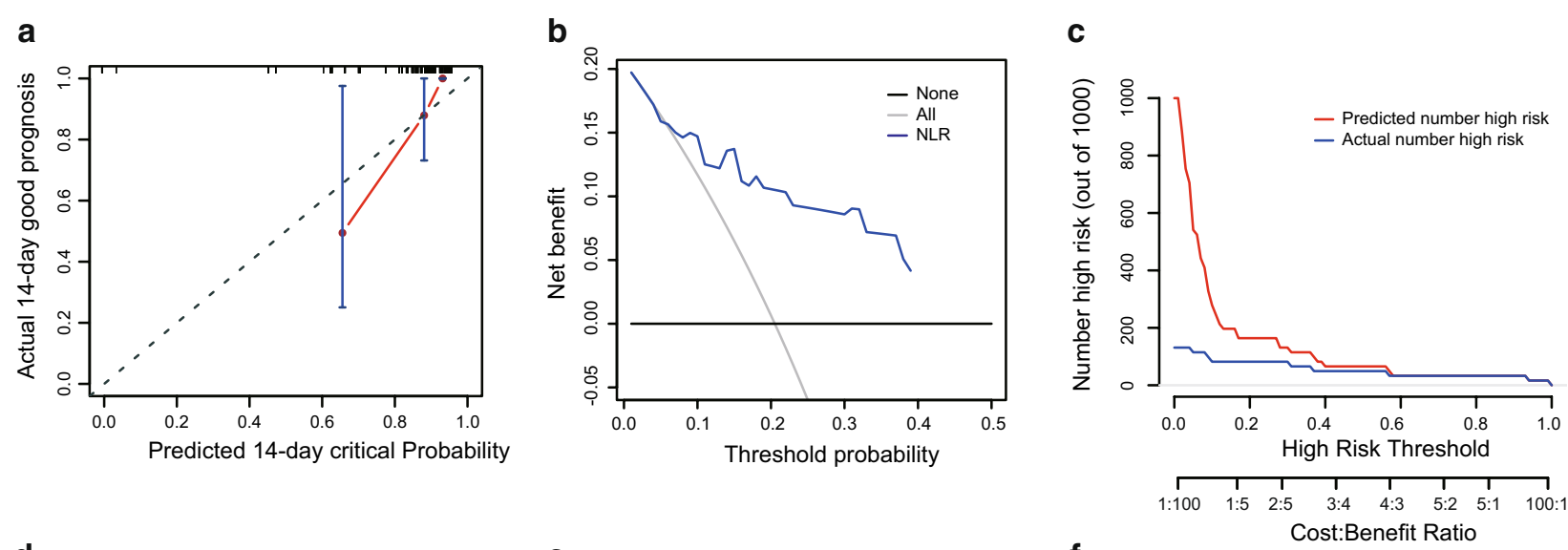

d

e
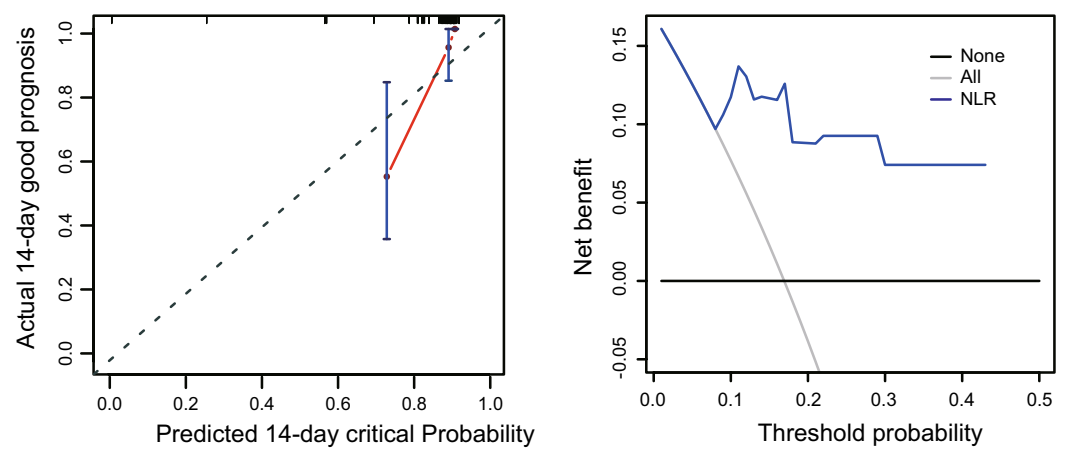

f

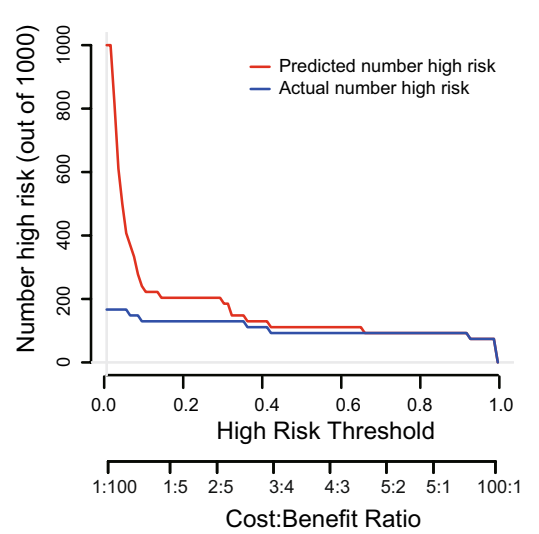

Fig. 4 Evaluate the prediction effect of nomogram in the derivation (a-c) and velidation ( $\mathbf{d}-\mathbf{f}$ ) cohorts. $\mathbf{a}$, $\mathbf{d}$ Calibration plot, $\mathbf{b}$, e decision curve and c, $\mathbf{f}$ clinical impact curve of the nomogram for critical probability in the COVID-19 cohort, in which the predicted critical probability was compared well with the actual probability and had superior standardized net benefit

NLR had superior standardized net benefit and influence on the patient outcome (Fig. 4b, c, e, f).

The NLR values of the patients on the day of admission our hospital and on days 3 and 7 after admission were checked. Figure 5 shows the dynamic changes at different times in patients with COVID-19 classified in the mild or moderate, and severe or critical groups. The NLR values were higher in the severe or critical group on admission and increased more rapidly compared to those in the mild or moderate group ( $\mathrm{p}=0.0240$ and $\mathrm{p}<0.0001$ for derivation and validation cohorts, respectively).

\section{Comparison NLR with other models}

Using receiver operating characteristic analysis, the predictive value of the NLR for the incidence of critical illness was compared to that of the MuLBSTA [11] and CURB-65 [12-14] models. NLR had the highest area under receiver operating characteristic curve (AUC) 


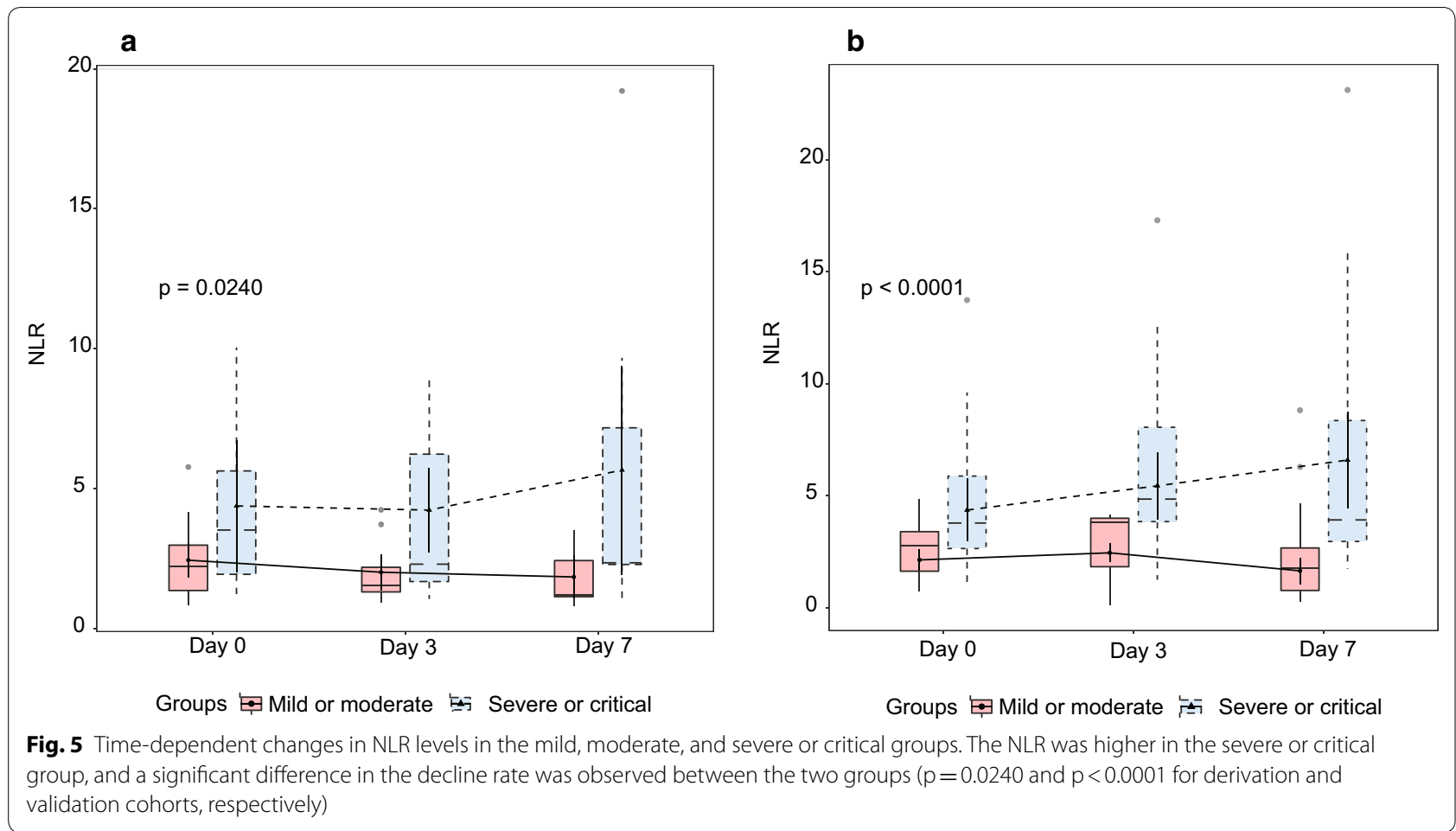

Table 2 Predictive value of the NLR, MuLBSTA and CURB-65

\begin{tabular}{|c|c|c|c|c|c|c|c|c|}
\hline & $\begin{array}{l}\text { AUC } \\
(95 \% \mathrm{Cl})\end{array}$ & $\begin{array}{l}\text { c-index } \\
(95 \% \mathrm{Cl})\end{array}$ & $\begin{array}{l}\text { SEN } \\
(95 \% \mathrm{Cl})\end{array}$ & $\begin{array}{l}\text { SPE } \\
(95 \% \mathrm{Cl})\end{array}$ & $\begin{array}{l}\text { PPV } \\
(95 \% \mathrm{CI})\end{array}$ & $\begin{array}{l}\text { NPV } \\
(95 \% \mathrm{Cl})\end{array}$ & $\begin{array}{l}\text { DLR positive } \\
(95 \% \mathrm{Cl})\end{array}$ & $\begin{array}{l}\text { DLR negative } \\
(95 \% \mathrm{Cl})\end{array}$ \\
\hline NLR & $\begin{array}{l}0.849 \\
(0.707-0.991)\end{array}$ & $\begin{array}{l}0.807 \\
(0.676-0.938)\end{array}$ & $\begin{array}{l}0.875 \\
(0.473-0.997)\end{array}$ & $\begin{array}{l}0.717 \\
(0.577-0.832)\end{array}$ & $\begin{array}{l}0.318 \\
(0.200-0.955)\end{array}$ & $\begin{array}{l}0.974 \\
(0.823-0.987)\end{array}$ & $\begin{array}{l}3.092 \\
(1.871-5.109)\end{array}$ & $\begin{array}{l}0.174 \\
(0.028-1.100)\end{array}$ \\
\hline MuLBSTA & $\begin{array}{l}0.762 \\
(0.585-0.938)\end{array}$ & $\begin{array}{l}0.771 \\
(0.659-0.883)\end{array}$ & $\begin{array}{l}0.875 \\
(0.473-0.997)\end{array}$ & $\begin{array}{l}0.679 \\
(0.537-0.801)\end{array}$ & $\begin{array}{l}0.292 \\
(0.184-0.949)\end{array}$ & $\begin{array}{l}0.973 \\
(0.822-0.986)\end{array}$ & $\begin{array}{l}2.728 \\
(1.703-4.370)\end{array}$ & $\begin{array}{l}0.184 \\
(0.029-1.162)\end{array}$ \\
\hline NLR-MuLBSTA & $\begin{array}{l}0.851 \\
(0.740-0.963)\end{array}$ & $\begin{array}{l}0.837 \\
(0.741-0.933)\end{array}$ & $\begin{array}{l}1.000 \\
(0.631-N A)\end{array}$ & $\begin{array}{l}0.679 \\
(0.536-0.801)\end{array}$ & $\begin{array}{l}0.320 \\
(0.205-N A)\end{array}$ & $\begin{array}{l}1.000 \\
(0.885-1.000)\end{array}$ & $\begin{array}{l}3.118 \\
(2.107-4.613)\end{array}$ & $\begin{array}{l}0.000 \\
(0.000-N A)\end{array}$ \\
\hline CURB-65 & $\begin{array}{l}0.700 \\
(0.505-0.896)\end{array}$ & $\begin{array}{l}0.744 \\
(0.573-0.915)\end{array}$ & $\begin{array}{l}0.625 \\
(0.245-0.915)\end{array}$ & $\begin{array}{l}0.755 \\
(0.617-0.862)\end{array}$ & $\begin{array}{l}0.278 \\
(0.168-0.712)\end{array}$ & $\begin{array}{l}0.930 \\
(0.722-0.965)\end{array}$ & $\begin{array}{l}2.548 \\
(1.247-5.208)\end{array}$ & $\begin{array}{l}0.497 \\
(0.200-1.232)\end{array}$ \\
\hline NLR-CURB-65 & $\begin{array}{l}0.889 \\
(0.743-1.036)\end{array}$ & $\begin{array}{l}0.870 \\
(0.762-0.978)\end{array}$ & $\begin{array}{l}0.875 \\
(0.473-0.997)\end{array}$ & $\begin{array}{l}0.868 \\
(0.747-0.945)\end{array}$ & $\begin{array}{l}0.500 \\
(0.310-0.978)\end{array}$ & $\begin{array}{l}0.979 \\
(0.855-0.992)\end{array}$ & $\begin{array}{l}6.63 \\
(3.17-13.86)\end{array}$ & $\begin{array}{l}0.144 \\
(0.023-0.904)\end{array}$ \\
\hline
\end{tabular}

$A U C$ area under curve, SEN sensitivity, SPE specificity, PPV positive predictive value, NPV negative predictive value, $D L R$ diagnostic likelihood ratios

(0.849, 95\% CI 0.707-0.991), and had higher sensitivity and specificity compared to those of the other two models in the derivation cohort (Table 2). In the validation cohort, the AUC of NLR was 0.867 (95\% CI 0.747-0.944), the sensitivity was 0.667 (95\% CI $0.299-0.925)$, and the specificity was 0.978 (95\% CI 0.882-0.999).

After NLR was incorporated into MuLBSTA (NLRMuLBSTA) and CURB-65 (NLR-CURB-65) models by adding the NLR value directly to the score of these two models, respectively, it was found that the prediction effect of the improved model was significantly better than that of the original model, but there was no significant difference between the AUC of NLR and those of NLR-MuLBSTA and NLR-CURB-65 ( $\mathrm{p}=0.9675$ and $\mathrm{p}=0.2971$, respectively) (Table 2 ).

\section{Stratifying patients according to risk}

The median follow-up time was 10 days, minimum 2 days and maximum 26 days. Patients were divided into two strata according to the cutoff value of NLR (low risk: $<3.13$; high risk: $\geq 3.13$ ) and age (age $<50$ years; age $\geq 50$ years). In the derivation cohort, progression to critical illness occurred in $2.6 \%(1 / 39)$ patients in the NLR $<3.13$ strata, $31.8 \%(7 / 22)$ in the NLR $\geq 3.13$ strata 

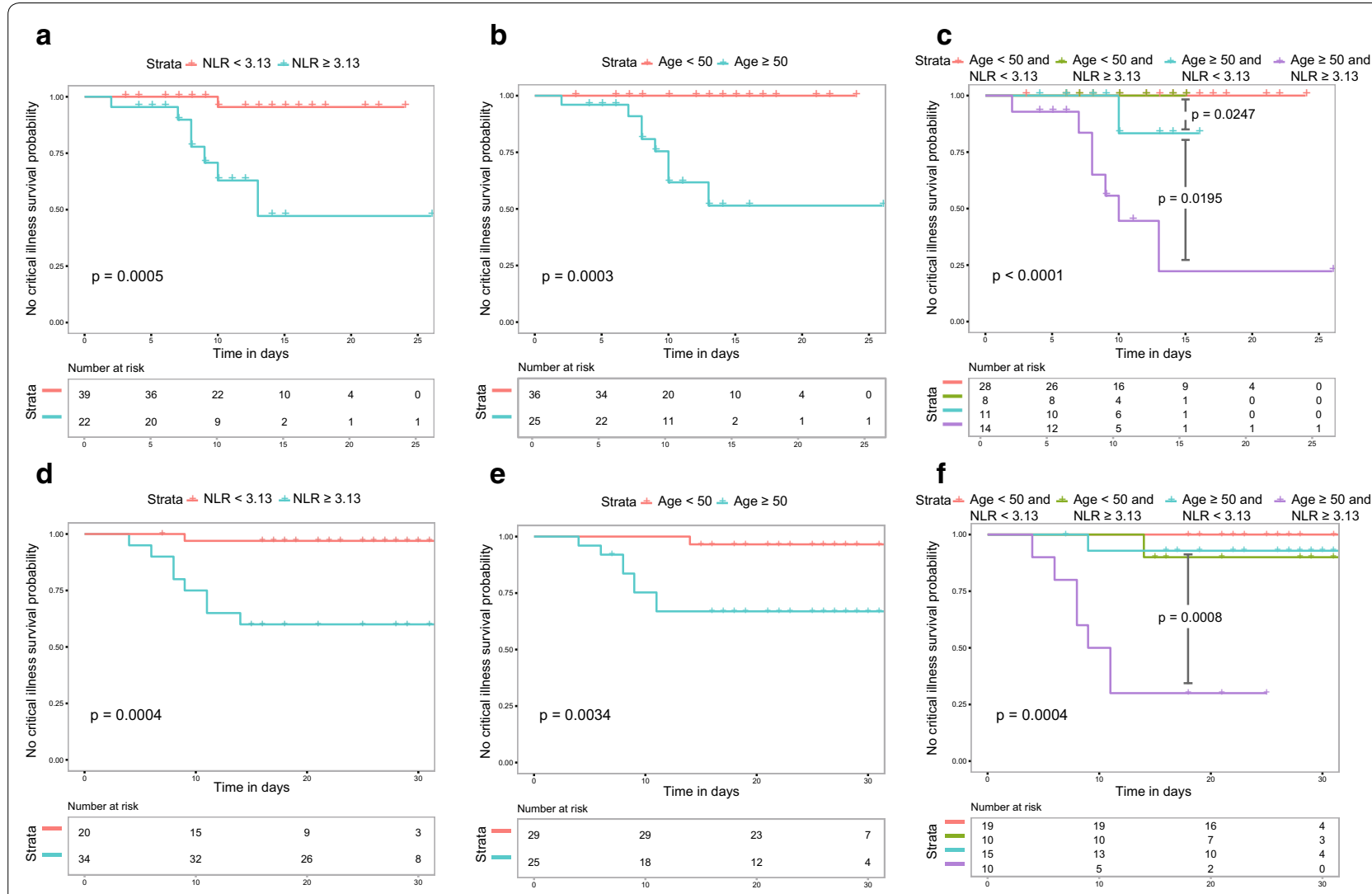

f

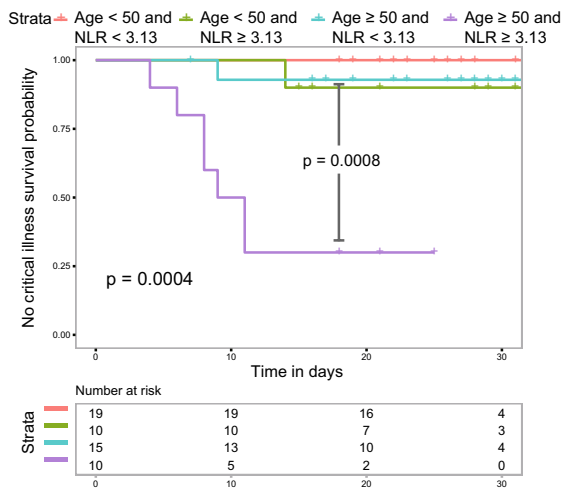

Fig. 6 Kaplan-Meier curves of risk group stratification for no critical illness in the derivation cohorts. a The cutoffs of NLR for each risk group were as follows: low risk: $<3.13$, and high risk: $\geq 3.13$. b Risk group stratification according to age and $\mathbf{c}$ NLR combined with age

$(\mathrm{p}=0.0005$, Fig. 6a), $0 \%(0 / 36)$ in the age $<50$ years strata, $32 \%(8 / 25)$ in the age $\geq 50$ years strata $(\mathrm{p}=0.0003$, Fig. $6 \mathrm{~b})$. In the validation cohort, progression to critical illness occurred in $2.9 \%(1 / 34)$ patients in the NLR $<3.13$ strata, $40 \%(8 / 20)$ in the NLR $\geq 3.13$ strata $(p=0.0004$, Fig. 6d), 3.4\% (1/29) in the age $<50$ years strata, $32 \%$ $(8 / 25)$ in the age $\geq 50$ years strata $(p=0.0034$, Fig. 6e). Furthermore, patients with COVID-19 pneumonia were stratified according to age and the NLR (strata 1: age $<50$ years and $\mathrm{NLR}<3.13$; strata 2 : age $<50$ years and NLR $\geq 3.13$; strata 3 : age $\geq 50$ years and $\mathrm{NLR}<3.13$; strata $4:$ age $\geq 50$ years and NLR $\geq 3.13$ ). In the derivation cohort, there was no critical illness case in strata 1 $(0 / 28)$ and strata $2(0 / 8)$; there was $9.1 \%(1 / 11)$ critical illness case in strata 3 and 50\% (7/14) critical illness cases in strata 4. As shown in Fig. 6c, the critical illness incidence was significantly different between strata 3 and 4 $(\mathrm{p}=0.0195)$ and between strata 2 and $3(\mathrm{p}=0.0247)$. In the validation cohort, there was no critical illness case in strata $1(0 / 19)$; there was $10 \%(1 / 10), 6.7 \%(1 / 15)$, and $70 \%(7 / 10)$ critical illness case in strata 2,3 , and 4 . As shown in Fig. 6e, the critical illness incidence was significantly different between strata 3 and $4(p=0.0008)$, but the difference between strata 2 and 3 was not significant $(\mathrm{p}=0.8317)$.

\section{Discussion}

Since the outbreak of the COVID-19 pneumonia in December 2019, there have been 2000 to 4000 new confirmed cases of infection every day in China, and the number of severe cases and deaths has also been increasing day by day. Recent research showed that $26 \%$ of patients received ICU care, and mortality was $4.3 \%$ [15]. The number of patients in Wuhan and other regions is increasing rapidly. The current difficulty is the shortage of medical resources, especially critical care resources. Early identification critical illness and risk stratification management will help alleviate insufficient medical resources and might reduce mortality. Recent studies have reported that low lymphocyte-to-C-reactive protein ratio [16], platelet-to-lymphocyte ratio [17], and thrombocytopenia [18] may be associated with critical illness. In addition, smoking and COPD have been associated with COVID-19 [19]. These may not have influenced the results in the present study because of the low number of subjects (a total of 10 smoking and 6 COPD patients). 
The COVID-19 pneumonia is not severe in the early stage, but the critical patients deteriorated on 7-14 days of illness course and entered a state of severe pneumonia and acute respiratory failure. The critical or death patients with COVID-19 infection were mostly of an old age and had comorbidities [20]. In the study, the critical ill patients were all over 50 years old. The decrease of lymphocyte count was related to the progress of the disease. It is unclear why lymphopenia is associated with severe illness. It has been hypothesized that COVID-19 may act on $\mathrm{T}$ lymphocytes, and $\mathrm{T}$ lymphocyte damage is an important factor that causes deterioration of the patient's condition [21]. In addition, a high leukocyte count is common in critically ill patients because damaged cells induce innate inflammation in the lungs, which is largely mediated by proinflammatory macrophages and granulocytes [22]. The NLR was a widely used marker for the assessment of the severity of bacterial infections and the prognosis of patients with pneumonia and tumors $[21,23-28]$.

In this study, the data of 115 patients with COVID-19 pneumonia were analyzed, the baseline characteristics of patients in the derivation and validation cohorts were described and compared, and the dynamic changes of laboratory indexes and imaging features were demonstrated. The independent risk factors affecting incidence of critical illness were screened. The results showed that NLR was the most important prognostic factor for progression, followed by age. Furthermore, according to the NLR and age stratification, the incidence of critical ill patients with $N L R \geq 3.13$ and aged $\geq 50$ years was $50 \%$, and $9.1 \%$ in aged $\geq 50$ years and NLR $<3.13$ patients.

Previous studies showed that the MuLBSTA score can give an early warning regarding the mortality of viral pneumonia; this score includes six indicators, namely, age, smoking history, hypertension, bacterial co-infection, lymphopenia, and multilobular infiltration [11]. The CURB-65 score was widely used to evaluate 30 -day mortality of patients with community-acquired pneumonia
[12-14]. In the study, NLR was compared with MuLBSTA and CURB-65 scoring models. The results showed that NLR had higher AUC, c-index, sensitivity and specificity, which indicated that NLR was better than the other two models for predicting the early incidence of COVID19 critical illness. Furthermore, it was found that the prediction effects of the NLR-MuLBSTA and NLR-CURB-65 models were better than those of the original models. But NLR was an easy-to-use predictor index.

The risk stratification of NLR according to age facilitates patient management. Patients aged $<50$ years with an NLR $<3.13$ highly unlikely to develop a critical illness and can be treated in a community hospital or home isolation; patients with NLR $\geq 3.13$ have a low chance of developing a critical illness need to be treated in a general isolation ward and closely monitored. Patients aged $\geq 50$ and having an NLR $<3.13$ have a moderate chance of developing a critical illness, and admitting to isolation ward with respiratory monitoring and supportive care was needed for these patients; patients aged $\geq 50$ and having an NLR $\geq 3.13$ have a high risk of developing a critical illness and need to be prepared for transfer to ICU for invasive respiratory support equipment (Fig. 7). If there are large-scale cases, the risk stratification and management will help alleviate the shortage of medical resources and reduce the mortality of critical patients.

There were some limitations to the study. First, we performed this study in low number of subjects (61 in the derivation cohort and 54 in the validation cohort). However, after we published our present study at medRxiv (https://medrxiv.org/cgi/content/short/2020.02.10.20021 584v1) on February 12, 2020, another group draw similar conclusion by a meta-analysis with 828 patients [16]. The status of patients in the derivation and validation cohorts may be different, leading to an imbalance in some laboratory indicators, such as white blood cell count, neutrophil count, and lymphocyte count. CRP [29], cardiovascular disease [30] and COPD [19] were not associated with COVID-19 in this study. These may be due to the low

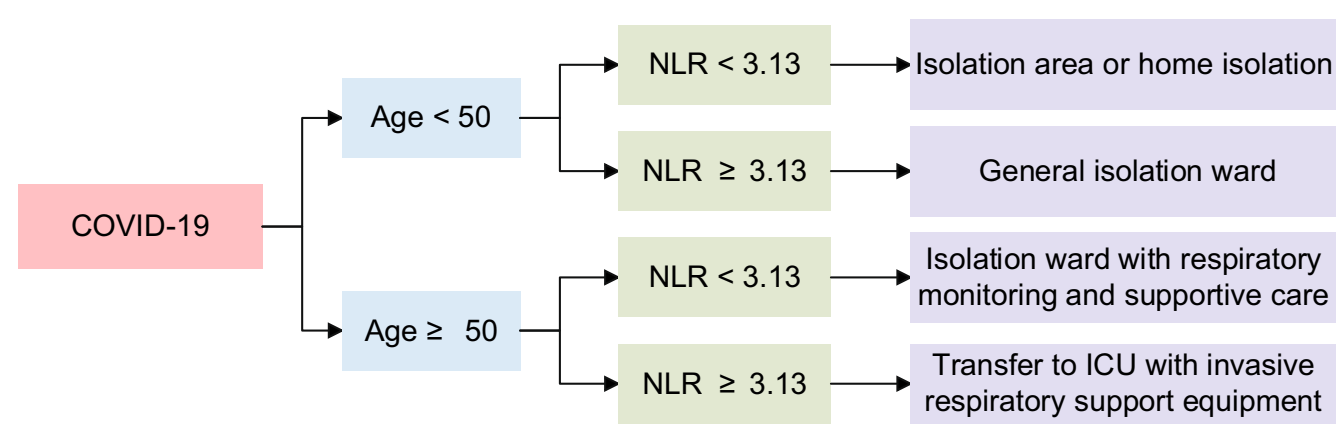

Fig. 7 COVID-19 pneumonia management process 
number of subjects. Future multicenter studies with large sample sizes are needed to explore the applicability of the risk stratification of NLR according to age in predicting the critical illness of COVID-19. Second, most of patients are still in hospital, whose condition maybe change in follow-up, and the study has not included the final survival outcome of patients. However, we focused on the early identification of critical cases for risk stratification and management. We expect that the risk model can help alleviate the shortage of medical resources and manage the patients with COVID-19 pneumonia.

\section{Conclusion}

The NLR was the most promising predictive factor for critical illness incidence of COVID-19 pneumonia. The early application of NLR and age will be beneficial to patient classification management and relief of medical resource shortage.

\section{Abbreviations}

AUC: Area under receiver operating characteristic curve; COVID-19: 2019 coronavirus disease; Cl: Confidence interval; ICU: Intensive care unit; NLR: Neutrophil-to-lymphocyte ratio.

\section{Acknowledgements}

We are grateful to Yi Ning, Ph.D., M.D. for his constructive comments in improving the language, grammar, and readability of the paper.

Our study suggested that neutrophil-to-lymphocyte ratio was the most significant factor affecting critical illness incidence of COVID-19. The risk stratification of NLR according to age facilitates patient management.

\section{Authors' contributions}

$J \mathrm{~L}$ and $\mathrm{YL}$ are joint first authors. XW, ZC, and $\mathrm{YW}$ contributed to the study design, implementation, manuscript discussion and critical revision. JL, $Y L, P X$, LP, HX, CL, MZ, JT, YX, RS, MS, LW, WZ, BH, LY, XJW, GZ, TZ and BL collected and interpreted the data. All authors read and approved the final manuscript.

\section{Funding}

None.

\section{Availability of data and materials}

The datasets used and/or analyzed during the current study are available from the corresponding author on reasonable request.

\section{Ethics approval and consent to participate}

This study was approved by the ethics committee of Beijing Ditan Hospital (Beijing, China). Informed consent from patients for their medical data to be used in the study were obtained.

\section{Consent for publication}

Not applicable.

\section{Competing interests}

The authors declare that they have no competing interests.

\footnotetext{
Author details

${ }^{1}$ Critical Care Medicine Department, Beijing Ditan Hospital, Capital Medical University, No. 8 Jing Shun East Street, Beijing 100015, China. ${ }^{2}$ Center of Integrative Medicine, Beijing Ditan Hospital, Capital Medical University, No. 8 Jing Shun East Street, Beijing 100015, China. ${ }^{3}$ Center of Infectious Diseases, Beijing Ditan Hospital, Capital Medical University, No. 8 Jing Shun East Street, Beijing 100015, China. ${ }^{4}$ Liver Diseases Center, Beijing Ditan Hospital, Capital Medical University, No. 8 Jing Shun East Street, Beijing 100015, China.
}

Received: 4 April 2020 Accepted: 12 May 2020

Published online: 20 May 2020

\section{References}

1. Kuiken T, Fouchier RA, Schutten M, Rimmelzwaan GF, van Amerongen G, van Riel D, et al. Newly discovered coronavirus as the primary cause of severe acute respiratory syndrome. Lancet. 2003;362(9380):263-70.

2. Drosten C, Gunther S, Preiser W, van der Werf S, Brodt HR, Becker S, et al. Identification of a novel coronavirus in patients with severe acute respiratory syndrome. N Engl J Med. 2003;348(20):1967-76.

3. de Groot RJ, Baker SC, Baric RS, Brown CS, Drosten C, Enjuanes L, et al. Middle East respiratory syndrome coronavirus (MERS-CoV): announcement of the Coronavirus Study Group. J Virol. 2013;87(14):7790-2.

4. Zaki AM, van Boheemen S, Bestebroer TM, Osterhaus AD, Fouchier RA. Isolation of a novel coronavirus from a man with pneumonia in Saudi Arabia. N Engl J Med. 2012;367(19):1814-20.

5. Holshue ML, DeBolt C, Lindquist S, Lofy KH, Wiesman J, Bruce H, et al. First case of 2019 novel coronavirus in the United States. N Engl J Med. 2020;382(10):929-36.

6. Huang C, Wang Y, Li X, Ren L, Zhao J, Hu Y, et al. Clinical features of patients infected with 2019 novel coronavirus in Wuhan, China. Lancet. 2020:395(10223):497-506.

7. Liu H, Zhang H, Wan G, Sang Y, Chang Y, Wang X, Zeng H. Neutrophillymphocyte ratio: a novel predictor for short-term prognosis in acute-onchronic hepatitis B liver failure. J Viral Hepat. 2014;21(7):499-507.

8. Harrell FE, Califf RM, Pryor DB, Lee KL, Rosati RA. Evaluating the yield of medical tests. JAMA. 1982;247(18):2543-6.

9. Chen Y, Huang F, Deng L, Yuan X, Tao Q, Wang T, et al. HIF-1-miR-219SMC4 regulatory pathway promoting proliferation and migration of HCC under hypoxic condition. Biomed Res Int. 2019;2019:8983704.

10. Vickers AJ, Elkin EB. Decision curve analysis: a novel method for evaluating prediction models. Med Decis Mak. 2006;26(6):565-74.

11. Guo L, Wei D, Zhang X, Wu Y, Li Q, Zhou M, et al. Clinical features predicting mortality risk in patients with viral pneumonia: the MuLBSTA score. Front Microbiol. 2019;10:2752.

12. Murillo-Zamora E, Medina-Gonzalez A, Zamora-Perez L, Vazquez-Yanez A, Guzman-Esquivel J, Trujillo-Hernandez B. Performance of the PSI and CURB-65 scoring systems in predicting 30-day mortality in healthcareassociated pneumonia. Med Clin. 2018;150(3):99-103.

13. Brabrand M, Henriksen DP. CURB-65 score is equal to NEWS for identifying mortality risk of pneumonia patients: an observational study. Lung. 2018;196(3):359-61.

14. Ilg A, Moskowitz A, Konanki V, Patel PV, Chase M, Grossestreuer AV, et al. Performance of the CURB-65 score in predicting critical care interventions in patients admitted with community-acquired pneumonia. Ann Emerg Med. 2019;74(1):60-8.

15. Wang D, Hu B, Hu C, Zhu F, Liu X, Zhang J, et al. Clinical characteristics of 138 hospitalized patients with 2019 novel coronavirus-infected pneumonia in Wuhan, China. JAMA. 2020;323(11):1061-9.

16. Lagunas-Rangel FA-O. Neutrophil-to-lymphocyte ratio and lymphocyteto-C-reactive protein ratio in patients with severe coronavirus disease 2019 (COVID-19): a meta-analysis. J Med Virol. 2020. https://doi. org/10.1002/jmv.25819.

17. Qu R, Ling Y, Zhang YH, Wei LY, Chen X, Li XM, et al. Platelet-to-lymphocyte ratio is associated with prognosis in patients with coronavirus disease-19. J Med Virol. 2020. https://doi.org/10.1002/jmv.25767.

18. Lippi G, Plebani M, Henry BM. Thrombocytopenia is associated with severe coronavirus disease 2019 (COVID-19) infections: a meta-analysis. Clinica Chimica Acta. 2020;506:145-8.

19. Leung JM, Yang CX, Tam A, Shaipanich T, Hackett TL, Singhera GK, et al. ACE-2 expression in the small airway epithelia of smokers and COPD patients: implications for COVID-19. Eur Respir J. 2020. https://doi. org/10.1183/13993003.00688-2020.

20. Chen N, Zhou M, Dong X, Qu J, Gong F, Han Y, et al. Epidemiological and clinical characteristics of 99 cases of 2019 novel coronavirus pneumonia in Wuhan, China: a descriptive study. Lancet. 2020;395(10223):507-13.

21. Liu WJ, Zhao M, Liu K, Xu K, Wong G, Tan W, et al. T-cell immunity of SARSCoV: implications for vaccine development against MERS-CoV. Antivir Res. 2017;137:82-92. 
22. Shi Y, Wang Y, Shao CA-O, Huang J, Gan J, Huang X, et al. COVID-19 infection: the perspectives on immune responses. Cell Death Differ. 2020;27(5):1451-4.

23. Berhane M, Melku M, Amsalu A, Enawgaw B, Getaneh Z, Asrie F. The role of neutrophil to lymphocyte count ratio in the differential diagnosis of pulmonary tuberculosis and bacterial community-acquired pneumonia: a cross-sectional study at Ayder and Mekelle Hospitals. Ethiopia. Clin Lab. 2019;65(4):527-33.

24. Chen $X Q$, Xue CR, Hou P, Lin BQ, Zhang JR. Lymphocyte-to-monocyte ratio effectively predicts survival outcome of patients with obstructive colorectal cancer. World J Gastroenterol. 2019;25(33):4970-84.

25. Feng DY, Zhou YQ, Zhou M, Zou XL, Wang YH, Zhang TT. Risk factors for mortality due to ventilator-associated pneumonia in a Chinese hospital: a retrospective study. Med Sci Monit Int Med J Exp Clin Res. 2019;25:7660-5.

26. Ge YL, Zhang HF, Zhang Q, Zhu XY, Liu CH, Wang N, et al. Neutrophil-tolymphocyte ratio in adult community-acquired pneumonia patients correlates with unfavorable clinical outcomes. Clin Lab. 2019;65(5):839-44.
27. Zhang HF, Ge YL, Wang HY, Zhang Q, Li WQ, Chen Y, et al. Neutrophil-tolymphocyte ratio improves the accuracy and sensitivity of pneumonia severity index in predicting 30-day mortality of CAP patients. Clin Lab. 2019;65(10):1867-73.

28. Liu H, Zhang H, Wan G, Sang Y, Chang Y, Wang X, et al. Neutrophil-lymphocyte ratio: a novel predictor for short-term prognosis in acute-onchronic hepatitis B liver failure. J Viral Hepatit. 2014;21(7):499-507.

29. Tan CA-OX, Huang Y, Shi F, Tan K, Ma Q, Chen Y, et al. C-reactive protein correlates with computed tomographic findings and predicts severe COVID-19 early. J Med Virol. 2020. https://doi.org/10.1002/jmv.25871.

30. Guo T, Fan Y, Chen M, Wu X, Zhang L, He T, et al. Cardiovascular implications of fatal outcomes of patients with coronavirus disease 2019 (COVID19). JAMA. 2020. https://doi.org/10.1001/jamacardio.2020.1017.

\section{Publisher's Note}

Springer Nature remains neutral with regard to jurisdictional claims in published maps and institutional affiliations.
Ready to submit your research? Choose BMC and benefit from:

- fast, convenient online submission

- thorough peer review by experienced researchers in your field

- rapid publication on acceptance

- support for research data, including large and complex data types

- gold Open Access which fosters wider collaboration and increased citations

- maximum visibility for your research: over 100M website views per year

At BMC, research is always in progress.

Learn more biomedcentral.com/submissions 